\section{Reflections on the conservation challenges of scientific and technological objects}

\author{
Reflexões sobre os desafios da conservação \\ de objectos científicos e tecnológicos
}

\section{LEMOS ${ }^{1 *}$}

I. TISSOT ${ }^{1,2}$ * (10)

1. Archeofactu, Rua do Cerrado das Oliveiras, n. ${ }^{\circ} 14,2 .^{\circ}$ dto, 2610-035 Alfragide, Portugal 2. LIBPhys-UNL, Campus da Caparica, 229-516 Caparica, Lisboa, Portugal

*isabeltissot@fct.unl.pt

\begin{abstract}
The conservation of science and technology (S\&T) heritage encompasses complex challenges. Among the reasons for this complexity are the $S \& T$ objects specific characteristics: the wide variety of materials, construction techniques and dimensions, and the existence of operating mechanisms. Present conservation methods are not fully adapted to the specificity of this heritage, requiring more research on S\&T conservation. This paper identifies the main challenges of S\&T objects conservation and gives guidelines to overcome them by i) increasing knowledge on materials and their degradation; ii) understanding the objects' function; iii) researching and developing new conservation techniques compatible with the characteristics of S\&T objects; and iv) creating decision-making tools for the definition and implementation of conservation and maintenance programs.
\end{abstract}

\section{Resumo}

A conservação do património da ciência e técnica (C\&T) constitui um complexo desafio no domínio do património cultural. Existem várias razões que justificam esta situação, entre as quais as características específicas dos objectos da C\&T: grande variedade de materiais, técnicas de construção e dimensões e a existência de mecanismos de funcionamento. Actualmente, os métodos de conservação utilizados são somente parcialmente adaptados às especificidades deste património e para ultrapassar este facto deve investir-se na investigação. Neste artigo identificam-se os principais desafios para a investigação da conservação do património da C\&T que estão relacionados com i) o aumento do conhecimento dos materiais e da sua degradação; ii) a compreensão da função dos objectos; iii) a investigação e desenvolvimento de novas técnicas de conservação compatíveis com as suas características; e iv) a criação de ferramentas que auxiliem no processo de tomada decisão no sentido da definição e implementação de programas de conservação e de manutenção.

\section{KEYWORDS}

Conservation

Objects of science and technology

Conservation methodologies Decision-making tools

\section{PALAVRAS-CHAVE}

Conservação

Objectos da ciência

e técnica

Metodologias

de conservação

Métodos para tomada

de decisão 


\section{Introduction}

The importance of scientific and technological (S\&T) objects as a primary source of information has consistently been recognised in different studies [1-2]. Nonetheless, their conservation is still a recent discipline when compared with conservation practices in other heritage areas [3]. Although S\&T heritage encompasses a broad range of scientific and technological objects - from fossils to herbaria and from vacuum pumps to motors -, in this paper we focus exclusively on collections of historical instruments resulting from teaching and research practices in the sciences.

The disparity of S\&T heritage conservation in the context of cultural heritage results from various factors, such as objects' diversity, dispersion and institutional custody, among others. Considering objects' diversity, scientific practices generate a large number of objects, with a variety of materials, dimensions, etc. Due to the impossibility of preserving all of them, the selection of what should be preserved is a complex exercise. Moreover, a precise definition of S\&T heritage is needed to delimit the area of preservation action. Finally, the institutional framework where S\&T heritage is produced generally lacks policies, mechanisms or resources for preservation. In addition, these institutions are out of culture institutions custody
[4]. This context leads, among others, to the existence neither of preservation policies nor skilled personnel to intervene in $S \& T$ instruments. Throughout the years, the restoration of $S \& T$ heritage has been focused on repairing and replacing elements and substituting paint and lacquer coatings. These actions were intended to keep the objects in operation, especially those with mechanisms [5-7], and with the original appearances disregarding historical value $[3,5]$. These restorations were often carried out by unskilled personnel, which led, in several cases, to irreversible loss of information.

As a result, for many years several crucial issues such as the characterisation and conservation of original surfaces, the presence of marks of use, and instruments' wear and tear, were not systematically approached. More recently, studies have identified the conservation of S\&T objects requirements, enhancing the need for detailed knowledge of the object's materials and function and underlining the importance of specialised training for conservator-restorers [8-9]. However, there is a lack of conservation methodologies and research guidelines in relation to S\&T heritage, coupled with a lack of training of conservators-restorers. To address this, a reflection on the challenges of S\&T objects' conservation is needed. This paper intends to contribute to this reflection by systematically identifying and exploring the main conservation issues and suggesting conservation research lines.

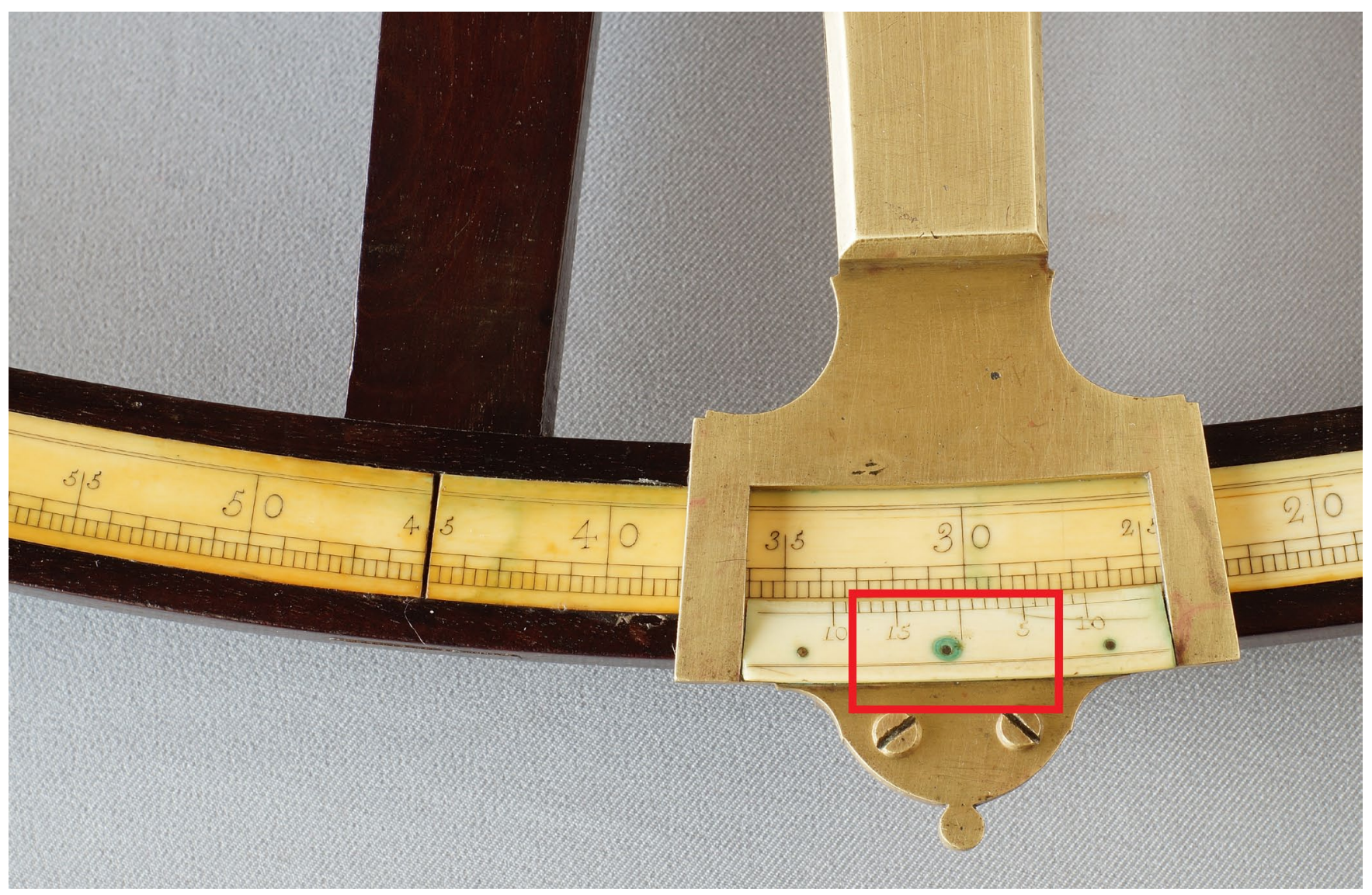

Figure 1. Detail of a nineteenth century sextant from the Museum of Lisbon, showing the ivory element degraded by the contamination of corrosion products from a copper alloy nail (photo: Matthias Tissot; courtesy Museum of Lisbon). 


\section{Challenges of S\&T objects conservation}

\section{Features of $S \& T$ objects and conservation constraints}

The main conservation challenges of $S \& T$ objects result from four of their features: materials, dimensions, function and moving components of mechanisms. Our aim here is to discuss in broad lines the constraints each one of these features imposes on conservation.

The wide range of objects that fall under S\&T heritage is reflected in a multiplicity of materials, such as wood, glass, metals, plastics, among so many others. From a strictly material perspective, three types of objects can be highlighted: i) composite objects; ii) objects containing toxic and radioactive components; and iii) objects manufactured with materials introduced in the second half of the twentieth century, what is commonly designated 'recent S\&T heritage'.

The conservation of composite objects can be complex as the degradation of one material can induce the alteration of the other. For example, Figure 1 shows the degradation of an ivory element from a sextant, induced by the corrosion of a copper alloy nail. This complexity is amplified if the degraded material is part of a structural element, jeopardizing the object's physical structure. Although conservation research on materials corrosion and degradation mechanisms largely exists, there are insufficient studies on analytical research of degradation of composite objects and, hence, limited information to establish conservation methods, ethics and practice.

Some S\&T objects are constituted by toxic and radioactive materials, as in the case of, instruments with chemical residues, radiographic equipment or photographic cameras. Hazardous materials are well signalled on some objects, while in others their presence is unsuspected [10]. The preservation of these objects requires identification protocols and procedures for handling, storage, transport and treatment, including decontamination and elimination [11-12]. Even though procedures to conserve these objects have been developed, their implementation is yet to be achieved [10]. In addition, decontamination or elimination procedures can result in a loss of original materials of an object, for example, the removal of radioluminescent paint from an element of an object, for safety reasons [10]. Needless to say, the procedures can also result in the total loss of objects, a matter that requires specific documentation protocols.

A significant number of $S \& T$ objects are manufactured with materials introduced in the second half of the twentieth century (e.g. plastics, iron-nickel and cobaltbased superalloys) [13-14]. The visual identification of these materials is often complex, particularly in the case of metallic alloys. Furthermore, knowledge of degradation processes is still scarce, hindering the definition of conservation procedures.

The second feature of S\&T objects with implications on conservation is their dimension. Objects can have large-scale
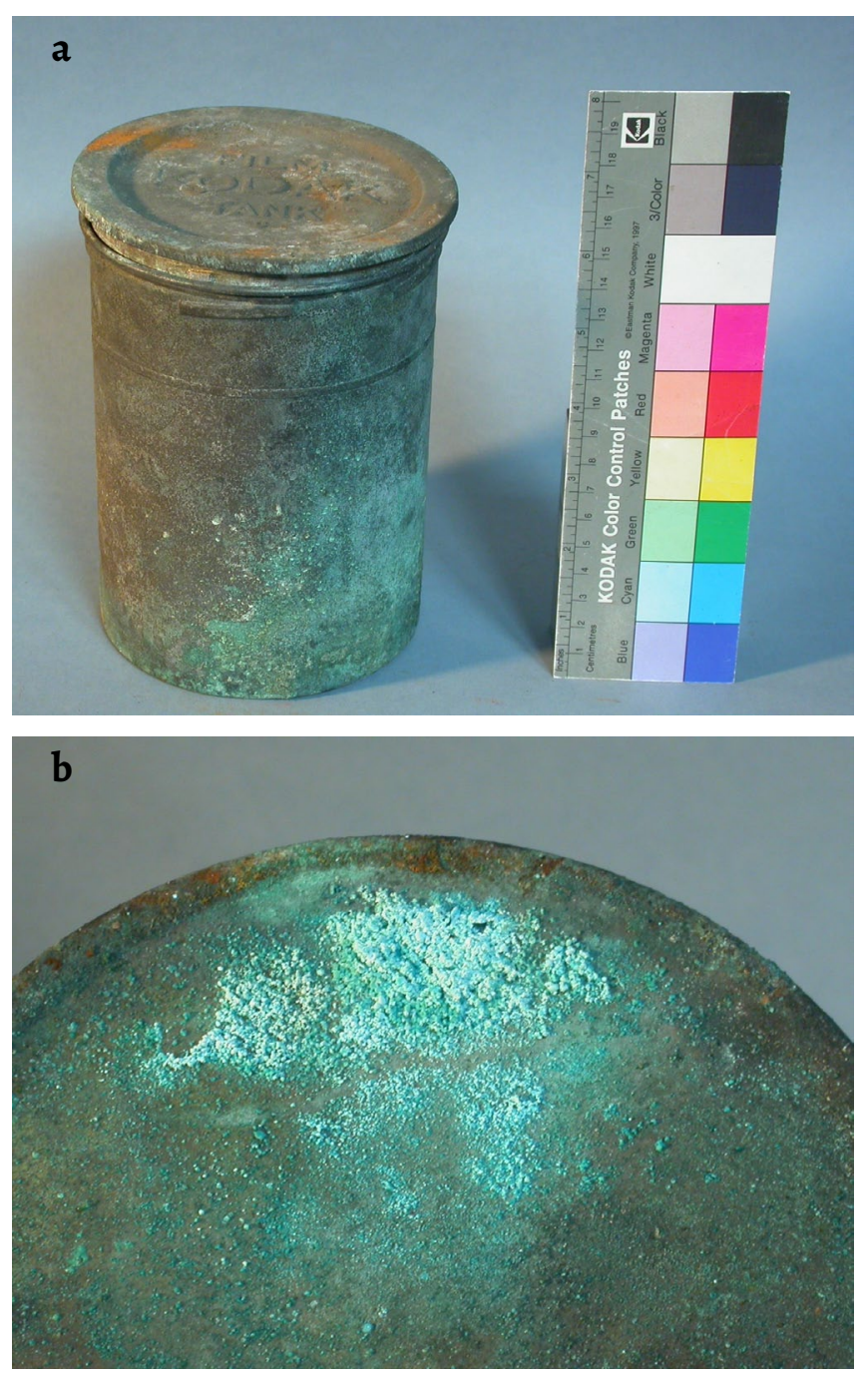

Figure 2. a) Kodak developing tank in copper alloy from MUHNAC; b) detail of the surface corrosion (photo: Manuel Lemos; courtesy MUHNAC, University of Lisbon).

dimensions in themselves or be composed of components with disparate scales as, for example, the Repsold-Merz meridian circle from the Lisbon Astronomical Observatory [15]. These characteristics lead to time-consuming and costly treatments, an aspect that can hinder the decision to preserve an object or a set of objects [16].

The third feature is function. The conservation of S\&T objects requires detailed knowledge of function and contextualisation, which can be highly specialised. Moreover, documentation about uses is generally lost or scarce. However, without this knowledge, a proper assessment of the conservation state of the object cannot be done, let alone the treatment without damage or vital information loss, such as marks of S\&T uses and practises.

Here we discuss two examples. The first is a Kodak developing tank in copper alloy from the National Museum of Natural History and Science (MUHNAC), University of Lisbon (Figure 2). The object shows an abnormal corrosion development as a result of the chemicals used for film developing. The nature of the corrosion products provided information on the chemicals used to develop the films. 


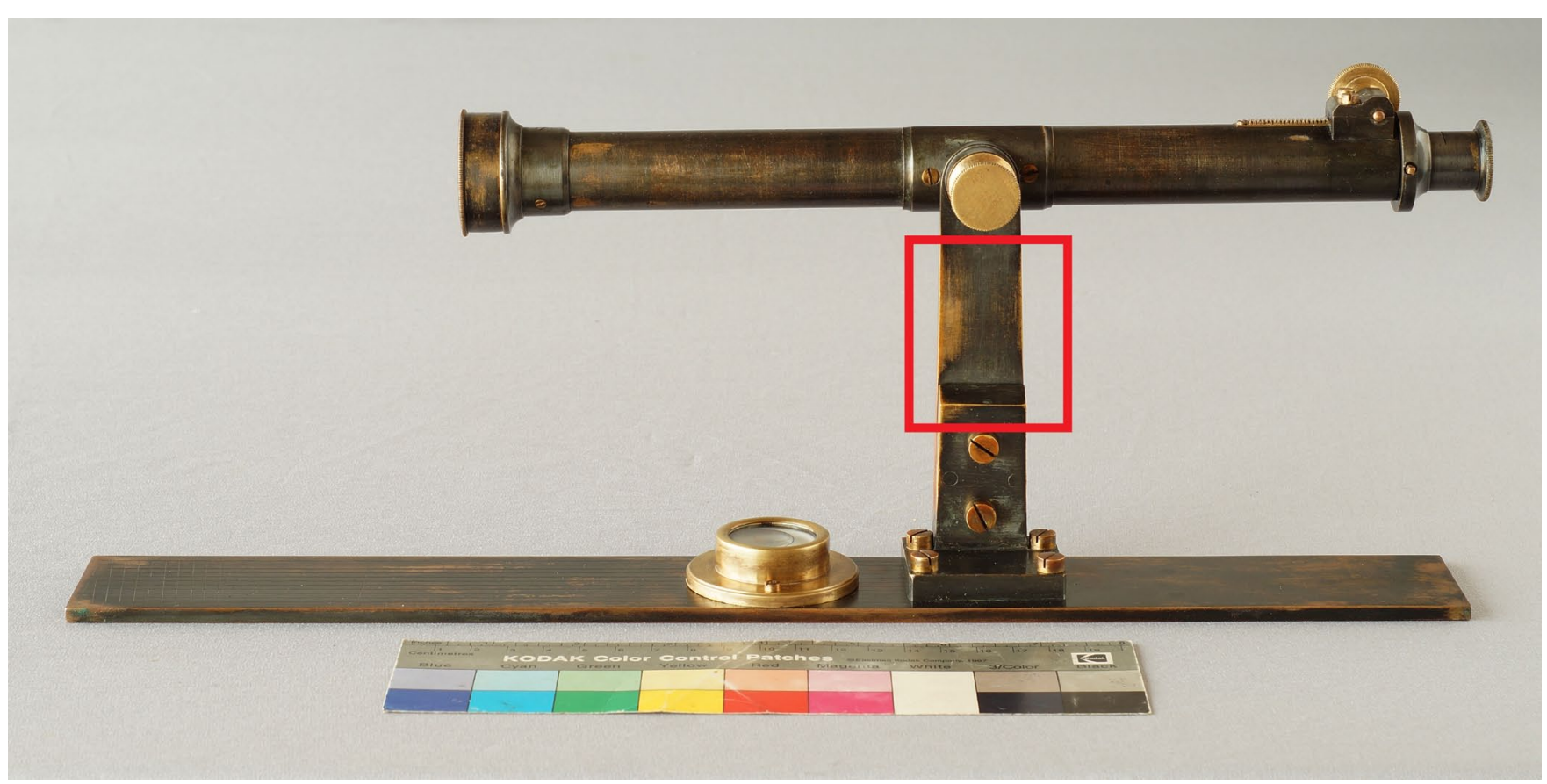

Figure 3. Nineteenth-twentieth century patinated copper alloy level from the Museum of Lisbon. The red rectangle highlights theareas with patina wear as a result of object use (photo: Matthias Tissot; courtesy Museum of Lisbon).

The second example is a copper alloy level, with an original black patina, from the Museum of Lisbon (Figure 3). This patina, probably composed of sulphur-based compounds, is worn out in specific areas. By knowing the function of the instrument is was possible to ascribe the patina lacunae to marks of use, as they correspond to parts mostly handled by users. These marks should be maintained as original information on object function and use. The specificity of the $S \& T$ heritage requires specialised conservator-restorers who are prepared to take into account object function and use, are aware that these do not always coincide and can engage on a peer-to-peer basis with historians of science, scientists and engineers, among others. Although in recent years there has been a reversal in the trend, conservatorsrestorers specialised in S\&T heritage are still scarce.

The last of the four features considers S\&T objects with mechanisms, i.e. systems of parts working together in an object to create movement. The movement is essential to understand objects' function and significance of objects. Preservation is often ensured by keeping the object in operation, raising questions related to historic value, longterm conservation and the sustainability of conservation maintenance programmes. Moreover, in order to preserve mechanisms, all parts need to be viable. This may not be possible because the object is too incomplete, cannibalised or damaged. And when it is possible, degraded materials, such as lubricants and rubber elements, may need to be replaced, leading to a loss of original parts [5] and authenticity issues. In addition, keeping an object in operation requires continuous maintenance and qualified staff to monitor and maintain the mechanisms, a problem for institutions with scarce human resources. Alternatively, S\&T objects with mechanisms can be preserved in partial or total static mode.
This option presents the advantage of preserving original parts. However, it poses risks to mechanisms' preservation because the lack of movement can induce physical degradation of the elements, for example the formation of cracks resulting from constant static load in one direction [17-18]. Furthermore, in both conservation options - static or operational mode - the maintenance and treatment of mechanisms, including moving components, require the implementation of methodologies outside the traditional conservation framework. The complex issue of conserving mechanisms in scientific instruments is somehow similar to the conservation of Kinetic art sculptures, in which the moving parts of mechanisms should be conserved to ensure movement [19] or, even, musical instruments.

Table 1 resumes the above-discussed conservation constraints established by S\&T object's features - materials, dimensions, function and mechanisms. Understanding these constraints enables a clearer definition of the main challenges of S\&T objects' conservation. From our point of view, those challenges are: i) increasing knowledge on materials, construction techniques, alteration, and corrosion mechanisms; ii) developing new treatments, suitable to the specific characteristics of S\&T objects; and iii) developing decision making and management tools for the conservation of mechanisms.

\section{Overcoming challenges}

In a way similar to the conservation of cultural heritage in general, conservation of S\&T heritage needs to be based on sustainable strategies that should be well-planned, actionoriented, collaborative and needed to be adapted to different levels of development. We briefly analyse below broad guidelines that we consider essential to define conservation 
Table 1. S\&T objects features related to the current main conservation constraints.

\begin{tabular}{|c|c|c|}
\hline \multicolumn{2}{|c|}{ S\&T objects features } & \multirow{2}{*}{$\begin{array}{l}\text { Conservation constraints } \\
\text { Limited knowledge on mutual degradation processes }\end{array}$} \\
\hline Materials & Composite objects & \\
\hline & Toxic and radioactive materials & Hazardous handling and treatments \\
\hline & 2nd half of XIX and XX centuries materials & Limited knowledge on materials and degradation process \\
\hline Dimensions & Large-scale instruments & Time consuming and costly treatments \\
\hline Function & Specialised instruments & Need of specialised S\&T conservator-restorers \\
\hline \multirow[t]{2}{*}{ Mechanisms } & Moving components & Complex decision on static or dynamic conservation \\
\hline & & Time consuming and costly maintenance \\
\hline
\end{tabular}

strategies specific to S\&T heritage. Our non-exhaustive analysis is structured around two axes covering the constraints discussed in the previous section: $i)$ conservation assessment; and ii) conservation treatment methods.

The conservation of S\&T objects must be based on a detailed knowledge of materials. Material characterisation comprises the identification of substrates, coatings, lubricants, and degradation and corrosion processes. The material study should be preceded by an assessment of the instruments' conservation state, that will provide information on the nature of the materials, their chronological application and their usage [8]. For example, the characterisation of lubricants can give information on components usage and perceive which of them were submitted to more wear. To increase knowledge of the object's materials and degradation, a science-based study should be used towards their characterisation, often complemented with interactions with scientists, technicians and historians of science and technology to understand objects life cycles and associated documentation. Contrary to other cultural heritage objects, such as paintings and sculptures, analytical protocols for material and construction techniques of S\&T objects need to be defined and established.

Scattered studies describe the application of noninvasive examination and analytical techniques such as X-ray fluorescence spectrometry (XRF) for the identification of substrates, radiography and tomography for the characterisation of construction techniques [19] and electrochemical impedance spectroscopy for conservation assessment [20]. However, systematic methods to characterise substrates, coatings, lubricants, alteration, and corrosion products are non-existent. In addition, existing approaches to study the wear and tear, the presence of internal cracks and tensions among components, and on the monitoring of mechanisms, are still very scarce. These analyses are fundamental to substantiate choice of conservation methods. For example, the conservation of the mechanical planetary model Tellurium (1819), from the Conservatoire National des Arts et Métiers in Paris, was preceded by a tribological study using interferometry to identify wear of structural axes in function of the lubricants. The results were used to define the conservation programme [21].

More applied research into the use of analytical techniques such as acoustic emission, infrared thermography, and tribological methods [22-24] is needed. These techniques are commonly applied in the industrial and engineering areas but their application and validation for S\&T objects are still unexplored.

In relation to conservation treatments methods, current and common cleaning, stabilisation and protection methods used in S\&T objects are mainly materials-oriented and derived from methodologies traditionally used in other cultural heritage objects (i.e. paintings, sculpture, metallic objects). However, lubricants replacement or selective cleanings for different materials assembled together remain unresolved. In addition, as mentioned, these issues are largely conditioned by the specific characteristics of S\&T objects, such as the large-scale dimension of instruments and the presence of mechanisms.

Recent studies propose alternative conservation methods to overcome the above limitations. $\mathrm{CO}_{2}$ blasting in surface cleaning [25-26] and the use of TiSiC and amorphous carbon deposited by PVD as new lubricants [27] have been used before. $\mathrm{CO}_{2}$ blasting, used in a few objects from the Laboratorio Chimico of MUHNAC [26], has the advantage of non-interference of the cleaning agent (solid $\mathrm{CO}_{2}$ ) with the mechanisms and allows cleaning surfaces in a short time frame [25-26]. Solid lubricants have the advantage of being more chemically stable, when compared with traditional oil lubricants, and also protect the surface. However, according to Cornet [27], parameters such as film deposition and film thickness control need to be improved. Further research is needed to improve these emerging conservation methods and develop new ones that can give effective contributions to the conservation treatment of S\&T objects.

The definition of conservation strategies for objects with mechanisms is one of the most complex issues of S\&T heritage, with multiple approaches, such as objects authenticity, musealisation, and maintenance costs, among others. It is the issue where documentation and interdisciplinarity are most important and per se worth 
of a separate paper, particularly in the light of the recent increased use of S\&T objects as historical sources [4]. In any case, some remarks about conservation aspects can be made. As discussed in the previous section, it is possible to conserve mechanisms either in static or in operational mode. From a material point of view, the conservation in operation can cause wear and tear of the mechanism parts, thus decreasing the objects' lifespan. On the other hand, the option to conserve the mechanism in a static mode, without the maintenance of the movement components, can also induce material rupture [28]. In that sense, decision-making regarding conservation methods, and related maintenance programmes, should be based on detailed science-based mechanism studies and thorough risk assessment resulting from both static and operational modes.

Recently, several conservation decision-making models have been developed, mainly for application to historical buildings and sites [29-30] and kinetics sculptures [19]. Moreover, decision-making models are well-known and applied in the industry for contemporary equipment maintenance and replacement [31]. However, decisionmaking tools for the conservation of S\&T objects are yet to be developed, tested, and implemented, let alone integrated in time-based models orienting maintenance programmes. These tools will allow to i) structure the discussion among the different professionals involved in objects conservation (museum curators, conservator-restorers, historians, scientists, etc); ii) enlighten the decision in face of multiple risks; and iii) support the justification and documentation of the decision.

\section{Towards a S\&T conservation program}

In this paper, the conservation of S\&T heritage was discussed considering the specificities of the S\&T objects and current limitations of their conservation practices. The challenges of conservation of S\&T objects were discussed emphasising: i) existing limited knowledge on materials, manufacture methods, and their degradation processes; ii) the time-consuming and costly conservation treatments due to the large-scale objects and disparate scale components; iii) the complexity of mechanisms' conservation. After the conservation challenges were identified, some broad research lines were proposed, encompassing: i) the application of science-based techniques to objects' study, particularly wear and tear assessment; ii) the development and application of innovative conservation methods that can, among others, assure selective cleanings for different materials assembled together and lubricants replacement; and iii) the development and implementation of decisionmaking tools for the definition of conservation strategies and maintenance programmes.

In many respects, we are far from mainstream conservation research and before we have conservators-restorers aware of the issues discussed in this paper, considerable training efforts need to be made by higher education institutions.

The training of conservators-restorers specialised in S\&T heritage is a complex issue also worth a separate paper. However, it should be noted that there are institutions in Europe offering conservation courses with a specialisation on S\&T objects, namely the Haute-École Conservation Restauration (HE-ARC), in Switzerland, and the Fachhochschule Erfurt Konservierung und Restaurierung (FR \& K\&R), in Germany. Courses include topics such as the history of science and technology and conservation practices for S\&T objects.

In terms of applied research, and in Portugal, there are concrete perspectives to develop innovative interdisciplinary projects to address the challenges of S\&T objects conservation discussed in this paper. Collaborations with research groups from other scientific areas (e.g. physical engineering, mechanical engineering, corrosion science, history of science, technology and medicine) are being established. These scientific areas develop research that can be applied to S\&T conservation. Two examples are the projects we have been developing with MUHNAC, University of Lisbon, and, more recently, with the Department of Physics of the NOVA University of Lisbon (DP-UNL). With MUHNAC, and for the past 10 years, we have been developing a continuous background work to establish requirements for the conservation of $S \& T$ objects in the frame of broader and global issues of the S\&T heritage. With the DP-UNL we are developing analytical strategies based on distinct spectroscopy and exam techniques for the material characterisation and conservation assessment of scientific, technical and industrial heritage. The results of these projects will allow establishing conservation protocols and methodologies that are still undefined today. However, much more projects and collaborations are needed as the work perspectives remain numerous, complex, and largely outside the radar of mainstream conservation.

\section{Acknowledgements}

We are grateful to Marta C. Lourenço from MUHNAC, University of Lisbon/Portuguese Research Infrastructure of Scientific Collections, and Maria João Petisca for comments and suggestions to improve this paper. Part of the work falls under the scope of Fundação para a Ciência e a Tecnologia funded project IH4Future "Material Culture, Scientific Culture - Industrial Heritage for future" (PTDC/FIS-AQM/30292/2017).

\section{REFERENCES}

1. Anderson K.; Frappier, M.; Neswald, E.; Trim, H., 'Reading instruments: objects, texts and museums' Science $\mathcal{E}$ Education 22 (2013) 1167-1189, https://link.springer.com/ article/10.1007\%2Fs11191-011-9391-y.

2 Lourenço, M.C.; Gessner, S., 'Documenting collections: cornerstones for more history of science in museums', Science \& Education 23 (4) (2014) 727-745, https://doi.org/10.1007/ s11191-012-9568-z.

3 Newey, H., 'Conservation and preservation of scientific and 
industrial collection' Studies in Conservation 45 (1) (2000) 137139, https://doi.org/10.1179/sic.2000.45.Supplement-1.137.

4 Lourenço, M.; Wilson, L. 'Scientific heritage: reflections on its nature and new approaches to preservation, study and access' Studies in History and Philosophy of Science 44 (4) (2013) 744-753, https://doi.org/10.1016/j.shpsa.2013.07.011.

5 Pye, E., 'Challenges of conservation: working objects', Science Museum Group Journal 6 (2016), https://doi.org/10.15180/160608.

6 Keene, S., 'Instruments of history: appearance and evidence', in The restoration of scientific instruments: proceedings of the workshop held in Florence, December 14-15, 1998. Florence, Istituto e Museo di Storia dellaScienza, Le Letter, Florence (1999) 57-68.

7 Mann, P. R., 'Working exhibits and the destruction of evidence in the science Museum', The International Journal of Museum Management and Curatorship 8 (4) (1989) 369-387, https://doi.org/10.1080/09647778909515181.

8 Brandi, P., 'Considerações sobre o restauro de instrumentos científicos' Museologia.pt 4 (2010) 198-206.

9 Granato, M., 'Conservação e restauração de instrumentos científicos históricos', MAST Colloquia 9 (2007) 121-144, http:// site.mast.br/hotsite_mast_colloquia/pdf/mast_colloquia_9. pdf (accessed 2018-10-14).

10 Daval, M., 'Les substances radioactives dans les objets patrimoniaux. Comportement à adopter, solutions et actions possible', CeROArt(online) Egg 4 (2014), https://doi.org/10.4000/ ceroart.4160.

11 Slocum, N., 'Toxins in the collection: museum awareness and protection', M.A. dissertation, The State University of New York, New York (2018), https://digitalcommons.buffalostate. edu/museumstudies_theses/16.

12 Hawks, C.; Makos, K., 'Inherent and acquired hazards in museum objects implications for care and use of collections', Cultural Resource Management 23 (5) 31-37, https://home1.nps. gov/CRMJournal/CRM/v23n5.pdf (accessed 2018-10-14).

13 Crawford, C. B.; Quinn, B., '2 - The contemporary history of plastics', in Microplastic Pollutants, ed. C. B. Crawford \& B. Quinn, Elsevier, Amsterdam (2017) 19-37, https://doi. org/10.1016/B978-0-12-809406-8.00002-5.

14 Sims, C. T., 'A history of superalloy metallurgy for superalloy metallurgists' in Superalloys 1984: Proceedings of the Fifth International Symposium on Superalloys, ed. M. Gell, Seven Springs Mountain Resort Champion (1984) 399-419, https:/www.tms.org/superalloys/10.7449/1984/ Superalloys_1984_399_419.pdf (accessed 2018-10-14).

15 Raposo, P., 'The material culture of nineteenth-century astrometry, its circulation and heritage at the Astronomical Observatory of Lisbon', in Cultural Heritage of Astronomical Observatories: from Classical Astronomy to Modern Astrophysics, ed. G. Wolfschmidt, Hendrik Bäûler Verlag, Berlin (2009) 99-113, http://dx.doi.org/10.11588/monstites.2009.1.19915.

16 Staelens, Y.; Morris, D., 'Crossing the line - sustainability and large object conservation in museums and heritage collections', in Proceeding of Heritage 2010, $2^{\text {nd }}$ International Conference on Heritage and Sustainable Development, eds. R. Amoêda, S. Lira \& C. Pinheiro, Greenlines Institute, Barcelos (2010) 1183-1191, http://eprints.bournemouth.ac.uk/17064/.

17 Wain, A., 'The importance of movement and operation as preventive conservation strategies for heritage machinery',
Journal of the American Institute for Conservation, 56 (2017) 81-95, https://doi.org/10.1080/01971360.2017.1326238.

18 Ashton, J.; Hallam, D., 'The conservation of functional objects - an ethical dilemma', AICCM Bulletin 16 (3) (1990) 19-26, https://doi.org/10.1179/bac.1990.16.3.003.

18 Whittle, D., 'The application of a kinetic art assessment template to the conservation treatment of Frank Hinder's work Dark Triptych', AICCM Bulletin 33 (1) (2012) 12-19, https:// doi.org/10.1179/bac.2012.33.1.003.

19 Gessner, S.; Carmo, A. M., 'Le globe céleste de Schissler: enjeux d'histoire des sciences et de préservation du patrimoine International' in Preprints of the ICOM-CC 16th Triennial Conference, ed. J. Bridgland, ICOM, Lisbon (2011) paper 0902.

20 Hallam, D.; Thurrowgood, D.; Ogilvie, C., 'Corrosion, wear and corrosive wear; the story of lubrification systems in large technology object storage and use - Question and answer session' in Preprints of the Big Stuff: Care of Large Technology Objects, ed. A. Wain, Australian War Memorial, Canberra (2004), https://bigstuff.omeka.net/items/show/65/ (accessed 2018-10-14).

21 Aguila, E.; Vargiolu, R.; Zahouani, H., 'Étude de l'usure des mécanismes d'horlogerie antiques: application à la restauration du «Tellurium»' (1819), poster, École National d'Ingénieurs de Saint-Etienne (2016), https://jift2016. sciencesconf.org/100810 (accessed 2018-10-14).

22 Bagavathiappan, S.; Lahiri, B. B.; Saravanan, T.; Philip, J.; Jayakumar, T., 'Infrared thermography for condition monitoring - A review', Infrared Physics \& Technology 60 (2013) 35-55, https://doi.org/10.1016/j.infrared.2013.03.006.

23 Holmberg, K.; Helle, A., 'Tribology as basis for machinery condition diagnostics and prognostics', International Journal of Performability Engineering 4 (2) (2008) 255-269, http://paris. utdallas.edu/IJPE/Volo4/Issue03/V4N3Po6APLS.pdf (accessed 2018-10-14).

24 Carlomagno, G. M.; Maio, R. D.; Meola, C.; Roberti, N., 'Infrared thermography and geophysical techniques in cultural heritage conservation', Quantitative InfraRed Thermography Journal 2 (1) (2005) 5-24, https://doi.org/10.3166/qirt.2.5-24.

25 Schröter, J.; Domjan, A., 'Le nettoyage cryogénique des métaux : évaluation du procédé appliqué au patrimoine', Conservation-Restauration des Biens Culturels 34 (2016) 19-26.

26 Tissot, I.; Lemos, M., 'A conservação e restauro - o caso dos metais', in O Laboratorio Chimico da Escola Politécnica de Lisboa: História, Colecções, Restauro e Musealização, ed. M. C. Lourenço, Museus da Universidade de Lisboa, Lisboa (2013), 87-97.

27 Cornet, E., 'Vers une lubrification sèche pour le patrimoine horloger', CeROArt 4 (2014), https://doi.org/10.4000/ ceroart.4151.

28 Saeed, A.; Khan, Z.; Garland, N.; Smith, R., 'Material characterisation to understand various modes of corrosion failures in large military vehicles of historical importance', WIT Transactions on Engineering Sciences 72 (2011) 95-106, https://doi.org/10.2495/MC110091.

29 Kioussi, A.; Karoglou, M.; Labropoulos, K.; Bakolas, A.; Moropoulou, A., 'Integrated documentation protocols enabling decision making in cultural heritage protection', Journal of Cultural Heritage 14 (S3) (2013) e141-e146, https://doi. org/10.1016/j.culher.2013.01.007. 


\section{Lemos, I.Tissot}

30 Kim, C.-J.; Yoo, W.S.; Lee, U.-K.; Song, K.-J.; Kang, K.-I.; Cho, H., 'An experience curve-based decision support model for prioritizing restoration needs of cultural heritage', Journal of Cultural Heritage 11 (4) (2010) 430-437, https://doi.org/10.1016/j. culher.2010.03.004

31 Emovon, I.; Norman, R.A.; Murphy, A.J., 'An integration of multi-criteria decision making of inspection intervals for marine machinery systems', Applied Ocean Research 59 (2016) 65-82, https://www.sciencedirect.com/science/article/abs/pii/ So141118716301390?via\%3Dihub.
RECEIVED: 2018.10.15

REVISED: 2019.5 .3

ACCEPTED: 2019.5.30

ONLINE: 2019.6.20

\section{(c) (1) $(9)$}

This work is licensed under the Creative Commons.

Attribution-NonCommercial-NoDerivatives 4.0 International License. To view a copy of this license, visit:

http://creativecommons.org/licenses/by-nc-nd/4.o/deed.en. 